Jnl Soc. Pol. (2020), 49, 1, 125-143 C Cambridge University Press 2019. This is an Open Access article, distributed under the terms of the Creative Commons Attribution-NonCommercial-NoDerivatives licence (http://creativecommons. org/licenses/by-nc-nd/4.0/), which permits non-commercial re-use, distribution, and reproduction in any medium, provided the original work is unaltered and is properly cited. The written permission of Cambridge University Press must be obtained for commercial re-use or in order to create a derivative work. doi:10.1017/S004727941900014X

\title{
Understanding Policy Scandals in Historical Context: A Longer-Term Lens for Policy Analysis
}

\author{
PATRICK BROWN", RUBÉN FLORES ${ }^{* * * * *}$ AND ANDY ALASZEWSKI ${ }^{* * * *}$ \\ *Department of Sociology, University of Amsterdam, Nieuwe Achtergracht 166, 1018 WV \\ Amsterdam, The Netherlands \\ email: p.r.brown@uva.nl \\ ** School of Sociology, University College Dublin, Belfield, Dublin 4, Ireland \\ *** Department of Sociology, Maynooth University, Ireland \\ email: ruben.flores@ucd.ie \\ ***** CHSS, University of Kent, George Allan Wing, Canterbury CT2 7NF, UK \\ email: a.m.alaszewski@kent.ac.uk
}

\begin{abstract}
The emergence of and reaction to policy scandals has been usefully studied through comparative case studies. Far less attention has been devoted, however, to the study of such scandals in long-term historical context. With the aim of illuminating longer-term social processes which shape the likelihood that (health)care scandals emerge, we delineate three areas where such changes are visible: a) changing formats of social relations and emotions within and around care provision, and thereby understandings of and demands for compassionate care; b) heightened organisational and political sensitivity to failings; and c) changes in media reporting on healthcare failings, as well as in policy-makers' responsiveness to and manipulation of media. We consider the 2013 Mid Staffordshire scandal in the English National Health Service and the extant policy literature on this scandal to help illuminate the added analytical value of our long-term approach. In the final section we explore the interconnection of the three processes and how longer-term approaches open up new vistas for policy analysis.
\end{abstract}

\section{Introduction}

The emergence of and reaction to policy scandals, for example through public inquiries, has been usefully studied through comparative case studies. Far less attention has been devoted to the study of such scandals amid historical processes. Aiming to redress this gap, we develop an analytical framework attentive to how long-term social transformations bear on health policy-making. We argue that adopting a longer-term, historical perspective allows us to grasp important dimensions of policy discourses and changes that would otherwise remain unnoticed: for example, by allowing us to problematize simplistic narratives of worsening (health) care provision, or to reassess the significance of scandals for policy making. 
We illustrate our analytical framework in relation to prevailing analyses of a prominent recent scandal over poor quality healthcare: the 2013 Mid Staffordshire scandal in the English National Health Service (NHS) (henceforth 'the Scandal'). The literature on the Scandal has tended to stress two topics: that this scandal exposed a lack of compassion in parts of the English NHS, and that such failures are products of recent directions in healthcare governance and related financial pressures. While valid, such framings overlook longer-term socio-political changes that have recast understandings and practices of care, heightened sensitivities to care failures and increased collective willingness to allocate blame and take action. We then consider three areas where the influence of long-term societal changes bears especially strongly on welfare state policy making:

a) Changing formats of social relations and emotions within and around care provision, e.g. the informalisation of professional-patient relationships, which has transformed expectations and practices of care since the 19th century and especially since the 1950s (Flores and Brown, 2018; Wouters, 2007); b) Heightened organisational and political sensitivity to failings, e.g. adaptive responses by healthcare organisations in the face of threats to their reputation (Habermas, 1976; Rothstein, 2006; Warner, 2006); c) The changing role of news media and of policy-makers' engagement with and manipulation of these mediaincluding the growing sensitivity of news media to certain types of event, and the interaction between forms of media framing (Kitzinger, 2000) and problem construction by policy-makers (Butler and Drakeford, 2005).

Recent historically-oriented policy scholarship on care, care dysfunctions and scandals (e.g. Butler and Drakeford, 2005; Ferguson, 2007; Mold, 2010, 2015; Rothstein, 2006) underlines the importance of emotions, norms, institutional interests and public debate. Our framework, combining two pre-eminent sociopolitical theories of long-term developments regarding these four phenomena (Elias, 2000; Habermas, 1987, 1989), provides an effective yet parsimonious analytical basis for considering the gradual longer-term reconfiguring of emotions and practices (de Swaan, 1995; Elias, 2000), norms and values ('rationalisation of the lifeworld') around care; alongside the bureaucratising influences of power and financial constraints upon care practices, healthcare organisations, news media and policy-making ('rationalisation of the system') (Habermas, 1987, 1989).

The aim of this article is to outline the tripartite framework for analysing scandals and their policy dynamics, to raise questions regarding rationality crises in policy-making processes, while also problematising short-term tendencies in the study of policy. Policy scholars have long emphasised the impossibility of rational policy-making (Habermas, 1976; Lindblom, 1959) but if social, organisational and politico-media dimensions are interacting to produce more scandals and encourage dysfunctional responses, then this is especially concerning for healthcare and other areas of policy-making (see Lodge and Hood, 2002; Warner, 2015). 


\section{Care scandals and their influence on policy}

Policy scandals, in their broader sense, may involve relatively 'small events' which nevertheless can have large impacts on policy (Lodge and Hood, 2002:10), as a result of specific understandings of the events and attributed failings, as framed by various claims-makers, news media and emotions, thus putting pressure on policy-makers to respond amid institutional confines (Butler and Drakeford, 2005; Lodge and Hood, 2002). Care scandals are a particular type of policy scandal, where failings are typically attributed to specific (trusted) (para-)professionals and the policy frameworks in which they work, resulting in the suffering of specific users of welfare state services (see Hutchison, 2016).

While the impact of earlier health and social care scandals upon policy has been questioned (Butler and Drakeford, 2005; Cooter, 1995), more recent scandals within English healthcare contexts have left a more significant mark on prevailing conceptions of 'problems' and policy solutions (Warner, 2015). For the then editor of the British Medical Journal, the Bristol Royal Infirmary scandal represented a watershed moment where 'all changed, changed utterly' (Smith, 1998:1917). A new framework of 'clinical governance' seemed very much informed by this and other recent dysfunctions, even if the policy was more a coordinating and intensification of pre-existing tendencies. Dixon-Woods and colleagues (2011:1453) argue that it was the peculiar concentration of a number of scandals involving doctors within a short space of time within the late-1990s, as well as the degree of the moral failings and incompetence, that led to such a marked impact on policy and (the demise of self-) regulation.

One of the most influential recent scandals within the English NHS was that concerning hospital care standards within the Mid-Staffordshire NHS Foundation Trust (a local health provider-organisation in central England) (Hutchison, 2016). Significant levels of preventable mortality and severe neglect (dehydrated and unfed patients; poor pain management), even cruelty, were described across care contexts, particularly those involving older people (Francis, 2013a; Hutchison, 2016). The head of the inquiry into these failings made many recommendations to avoid recurrences of the 'appalling suffering of many patients' (Francis, 2013a: 3).

The politicisation of the findings and proposals in (prime) ministerial speeches suggested important new policies. The 2014 Care Act 'delivers key elements of the government's response to the Francis Inquiry into the awful events at Mid Staffordshire hospital' (c. 2014:1), while the Secretary of State emphasized 'the Francis effect' - with 'compassionate care starting to replace tick-box targets as the major focus on boards and wards' (Hunt, 2014:1).

Following the publishing of the Francis report, policy discussions frequently used the term 'compassion' both to describe what was missing in these care contexts and to prescribe future remedying plans for NHS policy (Greenhalgh, 2013; 
Hunt, 2014; Newdick and Danbury, 2013). The Inquiry report set the tone for the subsequent orientation towards compassion, advocating the 'engagement of every single person serving patients in contributing to a safer, committed and compassionate and caring service' (Francis, 2013a:18).

This framing was employed by the Prime Minister (Cameron, in Department of Health, 2013:1) and Minister responsible for health policy, Jeremy Hunt, in several commentaries on NHS failures: 'People join the NHS because they have innate decency, compassion and caring values that makes them give their life towards helping people get better when they're at their most vulnerable - but we have a system that all too often crushes that...' (Hunt, quoted in Winnett and Brogan, 2013:1). While some politicians' uses of the compassion framing tended to locate the cause of care shortcomings in the failures of individual health workers (Hutchison, 2016; Smajdor, 2013), structural-governance factors were commonly acknowledged in policy statements.

Even if the Scandal was not a 'watershed' of the magnitude of some recent scandals accompanied by inquiries, ongoing references to compassionate care across a wide range of health policy documents (e.g. Department of Health, 2016,2017 a) point to an enduring legacy of the main compassion framing of the Scandal. Current policy regarding patient 'nutrition and hydration' (Department of Health, 2017b), for example, repeats the strong orientation towards older people and echoes the Francis report's language in various ways - e.g. through 'a clear and demonstrable set of values (such as the 6Cs of Compassion in Practice) underpinning a culture of compassionate care and placing the people we care for at the heart of everything, makes a huge difference to patients, carers and to staff (2017b:11).

Much more could be said about the problematised concept of compassion, its meaning and its implications for care (see Flores and Brown, 2018; Smajdor, 2013) but these considerations lie beyond the scope of this article. Compassion is certainly not the only term that might have been used to conceptualise the care failings and appalling suffering that took place, and the framework we develop below is more focused on understandings and politicisations of breakdowns in care. Before attending to this focus, we briefly consider other policy-oriented literature around the Scandal.

\section{Towards an understanding of the Scandal? The predominance of a shorter-term lens}

When accounting for care failings within pockets of NHS healthcare practice, many academic analyses echoed the arguments developed in policy-making circles (noted above). In their commentary on the Scandal, Newdick and Danbury (2013) argued that the failure of compassion was the product of an under resourced service committed to reducing costs while struggling to meet 
central targets. This is a position echoed by others (Dixon-Woods et al., 2013; Pollock and Price, 2013) who follow Francis's assessment of the financial strain brought about by senior managers at Mid-Staffordshire as they pursued the high status, devolved form of governance of a Foundation Trust: 'The result was both to deprive the hospital of a proper level of nursing staff and provide a healthier picture of the situation of the financial health of the trust than the reality, healthy finances being material in the achievement of foundation trust status' (Francis, 2013a:45; cited in Pollock and Price, 2013: 2190).

Further commonly considered systemic influences undermining compassionate practice include the distraction of targets and proceduralism, the mixed loyalties of clinician managers, as busy healthcare workers seek to complete their allocated tasks while having to make quick decisions under intense pressure (see especially Francis, 2013b; Newdick and Danbury, 2013). The combination of these factors, amidst broader contexts of 'financial austerity, institutional instability and political anxiety', are cited as facilitating the ongoing 'institutional disengagement from patients' which culminated in poor care (Newdick

and Danbury, 2013:6). Other academic commentators (e.g. Beaussier et al., 2016) have noted that various agencies tasked with ensuring the quality of NHS care had failed to identify and deal with poor quality services.

Many of these recent approaches reflect recent trends within critical social scientific analyses of healthcare work, policy and organisations. These accounts often highlight the contradictions between orientations towards quality care and patients' feelings associated with person-centredness, and governance logics towards efficient healthcare based on encoded knowledge. The latter model is task-oriented and requires healthcare workers to make decisions based on national guidelines, as cogs in a healthcare machine rife with alienating incentives and cultures (Flynn, 2002; Bevan and Hood, 2006). Although such analyses illuminate important major tensions in health policy and the changing nature of healthcare work, they are limited in understanding the Scandal in three related respects. First, in seeking to explain what went wrong, they adopt the common typification of the Scandal and the language of compassion at face value (cf. Smajdor, 2013). Second, their short-term focus does little to consider what the Scandal has in common with other scandals, and what a more historically oriented analysis can teach us about care failings (see Ferguson, 2007; Hutchison, 2016). Third, extant analyses have overlooked the conditions that bring scandals and policy reactions into being, as well as the threats scandals pose to quality decision-making (Lodge and Hood, 2002; Warner, 2015).

\section{Insights from existing critical-historical perspectives}

In significant contrast to other accounts of the Scandal, Hutchison's (2016) historical comparative analysis locates this case in relation to several earlier 
scandals in child protection, medicine and social care. This approach echoes Butler and Drakeford (2005) in noting that failures in care, no matter how much suffering is involved, are neither necessary nor sufficient to generate scandals. Instead Hutchison gives an account of the 'very specific social, cultural and economic circumstances [in which] scandals emerge' (Hutchison, 2016:37), highlighting the 'common phases' shared by scandals:

Health scandals involve transgressions in the behaviour of health professionals ... [which] may have been previously accepted or ignored by staff and are suddenly constructed as problematic. Claims are subsequently made by individuals with personal interests who harness the media to construct narratives and disseminate their views ... [creating] new dynamics in the relationships between service users and the health professionals delivering health-care.

While scandals over the years have also been driven by insider careprofessionals as whistle-blowers (Dixon-Woods et al., 2011), the emphasis here on the relative power of 'claims-makers' (e.g. patients, carers, and/or professionals) seeking to bring a problem to wider attention - their access to media and politicians, and the successful way in which they use language to frame the problem in a particular light - follows in a wider constructionist tradition to analyzing social problems based on common features in their emergence (Best, 1990; Spector and Kitsuse, 1977). These constructionist insights are reflected in important related studies in the history of medicine, whereby scandals are further considered as: facilitating the development of, while resulting from interventions by, claims-maker organisations (see Mold, 2015 on patient organisations); involving shifting institutional interests and framings (see Cooter, 1995 on bioethicists); and as successfully highlighting a 'gap' between institutional practices and public values, amid wider contexts of shifting hierarchies (Mold, 2010, 2015).

These historical-constructionist perspectives help us understand why the Scandal emerged and impacted on policy, while the coalition and subsequent Conservative Governments did little in the face of ongoing claims around underfunding of the NHS and its impact on care quality. First, if scandals take place 'when private acts that disgrace or offend the idealised, dominant morality of a social community are made public and narrativized by the media, producing a range of effects from ideological and cultural retrenchment to disruption and change' (Lull and Hinerman, 1997: 3, cited in Dixon-Woods et al., 2011), then it would appear that some care failings are too systemic, while lacking a private dimension and specific carers to blame. A second common theme shared by the Scandal was the portrayal of innocent and vulnerable victims and high levels of harm (Hutchison, 2016). Third, the Scandal echoes the political conditions of the Ely hospital scandal of the late-1960s and Bristol scandal of the late-1990s in providing a reforming health minister with an opportunity to push his agenda for change (Butler and Drakeford, 2005). 
Though historical, Hutchison (2016) and Butler and Drakeford's (2005) studies share much in common with synchronic analyses using inter-country comparative designs (e.g. Boin et al., 2009; Lodge and Hood, 2002). These cross-case analyses assist in illuminating underlying mechanisms that are common to scandal-driven policy formation, as well as in teasing out aspects of the institutional contexts that shape these. What these studies also share is a rather short-term analytical focus around each case. This is very useful in denoting subtle policy shifts and trajectories, but neglects the many insights afforded by an attentiveness to longer-term socio-historical processes.

We see glimpses of such longer-term analytical orientations in classic constructionist approaches to social problems and policy. Best's (1990) work on scandals and scares around children emphasises the role of successful claims-makers but is also attentive to long-term changes in social conditions, by which developments in obstetric and public health interventions led to falling birth-rates and a related evolution of the role and value of the child within the family (see also Ferguson, 2007). In the next three sections we develop a longerterm analysis of the social and political factors that shape the changing nature of healthcare scandals.

\section{Changing norms of proximity, care and related tensions: a figurational perspective}

In developing our diachronic approach to policy analysis, we draw firstly on figurational researchers (e.g. Elias, 200o) whose approach to analysing evolving figurations of interdependent social actors is especially attentive to longer-term historical processes. At the heart of Eliasian analyses of social change is the mutual influence between chains of social relations (sociogenesis) - gradually changing in their relative density, interwovenness and proximity - and shifting emotional propensities (psychogenesis) - for example, towards self-restraint, empathy and identification with others. Elias (2000) describes long-term 'civilising processes' taking place in Europe between the middle-ages and the early twentieth century, whereby increasing proximity and interdependencies in social relations gradually shaped, and are shaped by, a changing emotional habitus. This emerging habitus is characterized by a widening of 'circles of concern' and empathy for others (de Swaan, 1995), and a related greater attentiveness to one's conduct in the presence of others. As the power asymmetries between various groups - employers and employees, parents and children, men and women and, of most interest to us, between healthcare professionals and patients - have gradually receded, so have interaction norms become more informal and negotiated (Wouters, 2007), and so has a habitus of self-awareness regarding emotional restraint and 'appropriate' comportment become more 'second nature' and essential. 
Such changes in norms of interacting and caring are apparent in the work of medical historians. Porter (2005:381), for example, highlights the contrast between the professional proximity of the early twenty-first century and the routine clinical encounters of the seventeenth or eighteenth century [where] anything more than the most perfunctory and formal physical contact - as, for example, that involved in pulse-taking - was extremely unusual between a doctor and a patient'. Similarly, while current care for older people continues to be marked by ageism (Bowling, 2007), the contrast between current norms and those of the early 1950s, where older patients received little in the way of curative care under geriatricians who rarely visited their long-stay wards (Jefferys, 2000; Raghuram et al., 2011), is striking. Jolley's (2004) study of change in paediatric care (1920-1970) draws on oral historical accounts which 'show that children did not have access to their parents and that the staff were construed as being nonhuman, largely because of an approach that lacked affection. Nurses did care about the children and about their anxieties and fears but did not show their emotions and hid the affection they had for the children' (Jolley and Shields, 2009:165).

Changing forms of, and expressions of emotions within, care have resulted from reducing asymmetries in power between professionals and patients - while also shaping these relations. Hierarchy and deference towards experts has diminished somewhat (Jolley and Shields, 2009) and, as a result, professionalpatient interactions have become more negotiated and the expression and management of emotional labour has arguably become more central to the care relationship - 'trust has to be won, and the means of doing this is demonstrable warmth and openness' (Giddens, 1990:121). Studies of interactions involving doctors and nurses from the 1960s and 1970s (Menzies Lyth, 1960; Stimson and Webb, 1975) indicate, generally speaking, greater emotional distance and much less negotiation than is seen as the norm in the 2010 .

There is therefore evidence to suggest that norms of care, alongside understandings of what sufficient care for particular groups in society should look like, have changed markedly since the 1950 s and even more so since the early nineteenth century. So whereas a short-term lens leads to invocations of narratives regarding worsening manifestations of bureaucracy undermining care (Newdick and Danbury, 2013; Smajdor, 2013) and examples of lamentable managerial and staff conduct (Francis, 2013a), a long-term historical perspective reminds us that this is not the first time claims regarding poor care have been heard (Butler and Drakeford, 2005; Jones, 1993; Martin, 1984).

Long before recent new public management tendencies in healthcare governance, campaigns against poor care for, and ongoing abuse of, older people in long-term care hospitals in the late-1960s (e.g. Robb, 1967) had significant effects on NHS policy, leading to the institution of a watchdog (Hospital Advisory Service) and a health ombudsman (Martin, 1984). First-hand accounts 
of doctors working in geriatric care in the NHS suggest that what would be considered as highly deficient neglect in the 2010s was standard practice in the 1950 os (see Jefferys, 2000). This shift indicates rather different norms of care that are remarkable in 2018 in the extent to which they were accepted by so many, with the exception of various foreign-trained doctors and emerging geriatricianspecialists who questioned them (Raghuram et al., 2011: 328-331). Common lived experiences of housing and hygiene have also changed dramatically, rendering very different basic standards and expectations of hygiene and cleanliness care in NHS hospitals.

These changes in socio-interactional and material care norms have important implications for understandings, expectations and practices of care - a relational 'process' aimed at 'meeting socially recognised needs' (Thelen, 2014: 41; our translation). Below we describe three specific mechanisms that heighten the propensity of care to breakdown in ways which arouse strong emotions: institutional lags; more informal care being less stable; and tensions in the recognition of needs shaped by organisational and social changes.

\section{Institutional lags}

If we further delineate care in terms of 'caring about' ('recognising a need for care'), 'caring for' ('taking responsibility'), 'care giving' (practices) and 'care receiving' (evaluating the meeting of needs) (Tronto, 2010:160), it becomes apparent that shifts in 'caring about' and evaluating care may shift relatively quickly while responsibilities and hands-on practices may shift more slowly (Tonkens, 2012), not least because these latter care practices are embedded within the deeply institutionalized structures of large welfare organisations.

In 19th century Britain, for example, policy makers had created a legal structure defining and categorising individuals requiring some form of state support because they were dangerous and/or vulnerable, including 'criminals', 'paupers', 'lunatics' and 'mental defectives' (Jones, 1993). Individuals so categorized were denied full citizenship and - amidst the eugenic scare of the early 2oth century - became a threat to the British 'race'. These categories of 'others', by their ascribed status of less than human, were accordingly placed in secure environments for their own welfare and that of society - languishing beyond the circles of concern of most British people (Jones, 1993).

As racialised eugenicist discourses fell into disrepute within post-war Britain, such categorisations were increasingly challenged as inhumane. For example in 1950 the National Council for Civil Liberties published a critique of the inhumane treatment of those categorized as 'mentally defective', entitled 50,000 Outside the Law. New health and welfare policy gradually replaced these legal categorisations, the offensive terminology and associated systems of care with more modern and humane systems. However institutionalised practices and thinking proved more resistant to reform, as evident in contemporary accounts 
of life on the 'long stay back wards' of mental hospitals and care for those with severe learning disabilites. The first wave of NHS scandals and inquiries into mental health and learning disability institutions (1968-1976) graphically document out-dated practices and 'inhumane' care (see Butler and Drakeford, 2005).

\section{Care interactions as more equitable, informal yet unstable}

Eliasian perspectives, alongside wider arguments in medical ethics (e.g. Schei, 2006), suggest that a gradual diminishing in professional power in relation to patients leads to interactions and patterns of care which are more susceptible to breaking down (Brown et al., 2015). De Swaan (1981) and Wouters (2007) point to the ways in which traditional power structures made the role expectations and duties placed on each actor very confining yet explicit. This was in various senses problematic, but also made care and patientprofessional interactions less complex to handle. Less formal interactions require a much more deft approach of 'mutual consideration' and negotiation (de Swaan, 1981:376) which some patients or professionals are better skilled to undertake than others (Flores and Brown, 2018).

Mol (2008:32) usefully problematises the active-patient/passive-patient dichotomy in noting that patients always 'have to do a lot' amid 'care', especially given tendencies towards 'choice' and negotiation which Mol links to modernist and policy ideals. In contrast, we locate norms and values around (health) care within historical processes of evolving figurations (see also Cooter, 1995: 262,265 ) - not least informalisation - which leads us to emphasise that those on the margins are typically less well equipped with the necessary emotion management and interaction habitus to make choice and negotiation 'work' for them. Frail older people, for example - marginalised by ageism amid a society where contributions via paid work are emphasized (Bowling, 2007; TaylorGooby, 2012), and endowed with a more stoical, less negotiating, habitus than younger generations - may be especially vulnerable to breakdowns amid care norms characterised by negotiation, assumptions of active rational consumers, and declining professional authority (Schei, 2006).

\section{Tensions involving the recognition of needs}

Eliasian analyses (Elias, 2000; Wouters, 2007) furthermore sensitise us to co-existing processes whereby, alongside the reducing hierarchical distance and increasing informality described already, a reduced feeling for stigmatized others (e.g. older people and the 'undeserving poor') may emerge in social contexts characterised by a widening of social distance between the mainstream and the marginalized. Growing inequality in England since 1980 has thus been associated with 'outsider' groups becoming more distanced and disregarded in various welfare state settings (Brown et al., 2015; de Swaan, 1981; Rodger, 2003; Taylor-Gooby, 2012). Policies which have sought to enhance the power of 
the patient and to challenge the authority of professionals will therefore have a variable impact in more informal, negotiated care conditions (de Swaan, 1981; Schei, 2006) and may, indirectly, furnish conditions where poor care for 'outsiders' becomes more common.

Policies associated with an increased recognition and concern for the wellbeing of caring professionals may similarly be inadvertently increasing social distance between professionals and vulnerable groups. Guidance that staff should no longer lift heavy patients in order to wash them and should use lifts and hoists, for example, may have a depersonalising effect, turning disabled patients into objects and reducing personal-embodied contact. Such rules may also dysfunction towards inhumane care (Rader et al., 2006: 42), especially where equipment is in short supply and time consuming to use, and where heavy older patients do not get bathed on some wards.

Finally, as Schei (2006) also notes, shifts towards more patient-centred, less hierarchical care have emerged at the same time as, and in significant tension with, a scientific-bureaucratisation (Flynn, 2002; Smajdor, 2013) and commodification of healthcare. Tendencies for patients to be reduced to a set of risk factors, procedures, throughput or other distancing logics result from these latter phenomena (Greenhalgh, 2013). Traditional beliefs, values and norms - regarding medical authority, the inferiority or inherent dangerousness of various vulnerable groups, and related care practices - have been challenged and reformed through public debates led by professionals, patients and carers. However this 'rationalisation' of the lifeworld and everyday practices has nevertheless been undermined and warped by enduring power structures, institutional sluggishness and intensifying bureaucratisation of the system (Habermas, 1987). Tensions between these two long-term processes makes gaps between public understandings and organisational practices more likely.

\section{Heightened organisational sensitivities to dysfunction: an increasing responsiveness to scandals}

Not only have long-term shifts in social structures and emotional habitus made practices and perceptions of inappropriate care more likely, but overarching institutional governance has also become more attuned to recognizing failings (Power, 2004; Rothstein, 2006). Historical accounts of the early NHS denote a rather different way in which concerns of poor care were handled (Martin, 1984). Complaints raised by Robb (1967) and others about long-term care for older people were first contested, then dismissed by investigating committees. It was not until a further newspaper report of abuse occurring at Ely hospital, Cardiff - providing long-term care to adults with various levels of learning difficulties and psycho-geriatric patients (Howe, 1969) - that more serious changes were instituted (Martin, 1984). 
Less asymmetric healthcare hierarchies, as sketched in the sections above, render care professionals and welfare state organisations more accountable and, in many cases, more responsive to patients and the public than was the case in the 1960 s. The NHS and the professionals who staffed it were in various senses still venerated and deferred to in the 1950s and 1960s (Stimson and Webb, 1975), especially senior professionals (Jolley and Shields, 2009). A greater skepticism towards professionals and expert systems amongst more recent generations (Giddens, 1991) renders concerns of wrong-doing or failures more likely to be uttered. Patients', relatives' and front-line professionals' concerns or complaints are also more likely to be heard, partly assisted by the reporting and complaints (including whistle-blowing) systems which have gradually emerged since the early 1970 s (Mold, 2010), but also as a result of more general changes in the accountability structures which exist within late-modern public institutions. A language and organisational apparatus focused on ethics and quality improvement also makes professionals' questioning of existing practice more possible (Cooter, 1995:268; cf. Jolley, 2004).

The growing voice and power of patients - emerging out of reducing power asymmetries and legitimated and facilitated by policy (e.g. Department of Health, 1991; see Mold, 2010) - alongside the enhanced resources and authority of inquiries (Butler and Drakeford, 2005), has created a very different context in which complaints are considered. Whereas the answerable government minister suggested Robb's (1967) complaints constituted an abuse of free speech (Martin, 1984: 5), such a response would be less thinkable in the 2010s. To the contrary, a normalisation of inquiries has played an important role in amplifying and refashioning care scandals, rather than disputing them.

An 'inquiry culture' can be understood within wider developments in modern societies, such as increasingly refined understandings of the causality of many phenomena, which have been linked to a shrinking tolerance for unexplained events (Turner and Pidgeon, 1997; Wilkinson, 2010). Organisations, not least within the modern, bureaucratised and highly scrutinised welfare states, are compelled to find reasons for dysfunction; and, in various ways, this need to explain and to blame is bound up with organisational practices towards risk management (Power, 2004; Rothstein, 2006). Risks differ from dangers in that 'they are seen as the consequences of decisions' (Luhmann, 1993:101), with the ubiquity of risk management driven by the pressure to maintain 'myths of control and manageabilty' (Power, 2004:10), despite the limits of planning amidst pervasive uncertainty.

Warner (2006:223) analyses the growing trend of instituting inquiries into scandals within such a risk management framework. In her account, ideals of organisational learning and potential for future prevention serve rationalforensic functions, in attempting to comprehend what could be (and should have been) done differently, alongside a cathartic function including the 
apportioning of blame (see also Wilkinson, 2010:33). The social value of the inquiry response to scandal can therefore be seen 'as a reaction to the cultural experience of anxiety, in particular anxiety relating to rapid social change', despite various arguments questioning their effectiveness in learning and prevention (Warner, 2006:223).

Rothstein (2006) argues similarly that, over time, the priorities of such organisational attempts at learning become less oriented to the effective reduction of risks for clients or patients and instead the 'reputational risk' of the organisation becomes the key concern (see also Habermas, 1976). This warping of policy priorities may therefore explain both a growing sensitivity towards failure over time and the proliferation of dysfunctional policy-making, as lessons are learned and priorities are selected in a far from systematic way (Habermas, 1976; Lodge and Hood, 2002). At the national level, ministers and other policy-makers are required to show a zero-tolerance for care failings, as was visible in political reaction to the Scandal. At local level however, concerns with other forms of failings (such as financial or productivity) may distract from failings involving sub-standard care.

These organisational processes which warp institutional logics around risk and accountability must also be understood as influenced by the media (Rothstein, 2006). The ambivalence of media coverage of poor quality care prolonged indifference accompanied by occasional moral outrage (Butler and Drakeford, 2005) - helps fuel the dysfunctional reorientation of organisations away from patient vulnerability towards reputational risk. Longer-term changes in news media reporting, and its relationship to policy-making, is one further important feature of a historically sensitive account of the Scandal and its policy impact, to which we now turn.

\section{Pressures on governance: the changing role of media in generating scandals}

Habermas's (1989) description of the role of news media in facilitating rational discussion within the small public sphere of various eighteenth century polities has been critiqued as overly romanticized, but this account nevertheless serves to emphasize the longer-term effects of media commercialisation and corresponding instrumentalisation, especially in the later twentieth century: 'This expanded public sphere, however, lost its political character to the extent that the means of "psychological facilitation" could become an end in itself for a commercially fostered consumer attitude' (Habermas, 1989:169). Habermas charts this shift in terms of the oligopolistic development of the newspaper printing industry, the technological and capital requirements of more recent electronic media, and the corresponding instrumentalisation of newspaper editorship. 
In its overarching goal of building large and stable numbers of viewers or circulation, the mass media correspondingly has become a vehicle of publicity (Habermas, 1989), used by a range of state and private interests. Such instrumentalisation of editorial decisions results in the salience of various reliable rules and norms regarding the characteristic components of 'good' (sellable) stories - with these rules coming to dominate editorial judgements (Negrine, 1994). Hughes and colleagues (2006:256-8) identify various features of 'newsworthiness': high levels of harm where those affected can be linked to the audience; potential moral dimensions in terms of blame; as well as the nature of the people involved for example innocent victims. It is in light of these rules that the 'marketability' of some lapses in healthcare (e.g. the neglect of frail older people exposed by the Scandal) but not others (more systematic underfunding) becomes further comprehensible. Imperatives to cover such stories place the NHS and other welfare institutions (such as child protection services) under an especially sensitive media gaze (Warner, 2006). Such coverage is rooted in, while also gradually shifting, lifeworlds of understandings, norms and values around particular vulnerable groups and their needs.

One further marketable characteristic of a story relates to the potential for it to be framed in terms of a familiar narrative, albeit with a novel quality or twist (Alaszewski and Brown, 2012; Negrine, 1994). The prior existence of memorable, iconic events or scandals (Butler and Drakeford, 2005) would therefore seem to heighten the likelihood that later occurrences, ostensibly similar in nature, will attract media attention (Warner, 2006) - due to the 'meaningful' resonance of these events as 'interpretable within the cultural framework of the listener or reader' (Galtung and Ruge, 1965: 66-7). Past scandals involving healthcare dysfunctions and lapses in dignified care, alongside a general attentiveness to NHS failings, can thus be seen as making it more likely that the problems within Mid-Staffordshire received significant amounts of media coverage, helping 'transform' suffering into a scandal (Butler and Drakeford, 2005) in a rather different manner than would have been likely a half century earlier.

These heightened accountability pressures facing welfare state organisations have rendered governments and policy-makers increasingly sensitive to media reporting and the related reputational risk (Rothstein, 2006). In turn, governments have become increasingly skilled and organized in managing and deflecting media criticism: for example, in working with cases of failure to politicize concerns and mobilize support for certain forms of change (Boin et al., 2009).

In reacting to media coverage, governmental actors are thus also able to shape media interest, either through distracting from and ignoring potential scandals, or by fueling and legitimising concerns in attempting to ensure a certain account of a scandal - such as an apparent breakdown in professionals' compassion - becomes defining (Butler and Drakeford, 2005; Warner, 2015). Inquiries have become a fundamental tool for governmental action within these 
contexts, as a means of showing action and taking problems seriously, offering short-term catharsis (Dixon-Woods et al., 2011) while deferring longer-term solutions, as well as assisting in the framing of new policy. But far from a linear process - whereby incident leads to scandal leads to inquiry, followed by policy - Butler and Drakeford (2005:5) describe a more 'complex, reciprocal relationship': for example, whereby existing political tensions make scandals within certain policy domains more likely.

In contrast then to the 1960 s when healthcare professions were more able, and ministers apparently more willing, to contest public concerns about care standards, a growing relative authority of lay concerns, alongside an increased political awareness and readiness amongst ministers to manipulate scandals for their own ends, represent a fundamental historical shift in political conditions. These conditions are salient in analyzing the emergence and influence of the Scandal in the years running up to 2013 and since.

\section{Conclusion}

The three main threads of our longer-term approach facilitate a rather different basis for analyzing the Scandal from that of the existing policy literature. This literature contains many valuable analytical and practical insights (e.g. Greenhalgh, 2013; Francis, 2013b; Newdick and Danbury, 2013), however there is also an extent to which political attentiveness to compassion is less critically reproduced (see Smajdor, 2013 for a more critical account). Constructionist approaches lead to quite different understandings of the Scandal (e.g. Hutchison, 2016), with those comparing scandals over time being especially insightful in describing recurring processes, language and outcomes (e.g. Best, 1990; Butler and Drakeford, 2005). Applying these critical policy frameworks points to a number of analytical weaknesses in the prevailing commentaries on the Scandal, as well as the need for a practical wariness regarding scandals and their disproportionate influence on policy-making (Lodge and Hood, 2002; Warner, 2006).

Whereas some insightful analyses compare multiple short-term case studies over time (Butler and Drakeford, 2005; Hutchison, 2016), our framework is oriented towards the interplay of long-term processes:

- How growing proximity and reducing hierarchy and formality in social relations gradually produce different care norms and furthermore enable possibilities for the questioning of care norms. At times this questioning is facilitated by news media criticism and debate, yet these processes exist alongside social, organisational and media processes associated with declining sympathy for some groups in society, lags in institutional practices, and the scientific-bureaucratisation of (health)care work. 
- Longer-term effects of 'changed popular expectations and a growing sensitivity to risk' (Moran, 2001: 19) have impacted on organisations, rendering a greater degree of accountability. Claims made by patients, carers, professionals and others are more likely to be heard, but various institutional logics addressing these claims can lapse into managing reputational risk, therefore stifling organisational learning and effective change.

- Various processes outlined in the two points above are themselves potently shaped by news media coverage. Editorial policies and their effects (such as those that elicit defensive organisational responses) have been understood as being driven by financial-instrumental market effects. We have also noted that news media reporting is used in various ways by policy-makers, using arguments that resonate with, contribute to, and warp emerging norms and values.

These processes involve changing social practices (see also Ferguson, 2007), changes in claims-making around these practices (see also Mold, 2010), and evolving structures of policy debate and emotions within which these claims are acted upon, reworked or ignored. In these senses a longer-term lens for policy analysis is salient to critically deconstructing individual policy problems and scandals, but also to raising wider concerns around the conditions in which policy is developed and enacted; not least the possibilities for reflexive refinement of policy lifeworlds amid rationalisation of systems (Habermas, 1987). Our analytical approach, combining an Eliasian sensitivity to shifts in street-level interactions and wider circles of emotional concern (de Swaan, 1995) with Habermasian (1987) considerations of long-term developments in the possibilities for public debate amid the warping effects of power, institutional logics and financial constraints, represents one useful toolbox for analysing shifting policy dynamics.

Further research is needed to interrogate the different features of our framework in more depth. If these long-term changes do indeed combine to render scandals more likely and more influential, then this represents a potential threat to effective and evidence-based policy-making (Lodge and Hood, 2002; Warner, 2015). Policy analysts can play an important role here, not least in using longer-term perspectives to inform how we evaluate social problems and to challenge overly short-termist understandings and solutions.

\section{Acknowledgements}

The authors are grateful to Iain Wilkinson, Rineke van Daalen and a number of other colleagues for feedback on earlier versions of this article and the ideas contained therein. An initial draft of this article was developed while Patrick Brown was a visiting researcher at the Risk and Crisis Research Centre, Mid-Sweden University and the extensive library facilities available there were especially useful in developing the analysis and literature review. 


\section{References}

Alaszewski, A. and Brown, P. (2012), Making Health Policy: a critical introduction. Cambridge: Polity.

Beaussier, A., Demeritt, D., Griffiths, A. and Rothstein, H. (2016), 'Accounting for failure: risk-based regulation and the problems of ensuring healthcare quality in the NHS', Health, Risk \& Society, 18, 3-4, 205-224.

Best, J. (1990), Threatened Children: rhetoric and concern about child victims, Chicago: University of Chicago Press.

Bevan, G. and Hood, C. (2006), 'What's measured is what's matters: targets and gaming in the English public health care system', Public Administration, 84, 3, 517-538.

Boin, A., t'Hart, P. and McConnell, A. (2009), 'Crisis exploitation: political and policy impacts of framing contests', Journal of European Public Policy, 16, 1, 81-106.

Bowling, A. (2007), 'Honour your father and mother: ageism in medicine', British Journal of General Practice, 57, 538, 347-348.

Brown, P., Elston, M.E. and Gabe, J. (2015), From patient deference towards negotiated and precarious informality: an Eliasian analysis of English general practitioners' understandings of changing patient relations. Social Science \& Medicine, 146, 164-172.

Butler, I. and Drakeford, M. (2005), Scandal, Social Policy and Social Welfare, Bristol: Policy Press.

Cooter, R. (1995), 'The resistable rise of medical ethics', Social History of Medicine, 8, 2, 257-270. de Swaan, A. (1981), 'The politics of agoraphobia', Theory and Society, 10, 3, 359-385.

de Swaan, A. (1995), 'Widening circles of identification: emotional concerns in sociogenetic perspective', Theory, Culture \& Society, 12, 2, 25-39.

Department of Health (1991), The Patients' Charter, London: HMSO.

Department of Health (2013), 'Prime Minister responds to Mid Staffs public inquiry report', https://www.gov.uk/government/news/prime-minister-responds-to-mid-staffs-publicinquiry-report [accessed 14 April 2016].

Department of Health (2016), 'The Government's Mandate to NHS England for 2016-2017', https:/www.gov.uk/government/uploads/system/uploads/attachment_data/file/600604/ NHSE_Mandate_2016-17.pdf [accessed 14 May 2017].

Department of Health (2017a), 'Compassionate care in the NHS', https://www.gov.uk/ government/policies/compassionate-care-in-the-nhs [Accessed 14 May 2017].

Department of Health (2017b), 'The Hospital Food Standards Panel's report on standards for food and drink in NHS hospitals', https:/www.gov.uk/government/uploads/ system/uploads/attachment_data/file/523049/Hospital_Food_Panel_May_2016.pdf [accessed 14 May 2017].

Dixon-Woods, M., Baker, R., Charles, K., et al. (2013), 'Culture and behaviour in the English National Health Service: overview of lessons from a large multimethod study', BMJ Quality and Safety, 23, 106-115.

Dixon-Woods, M. Yeung, K. and Bosk, C. (2011), 'Why is UK medicine no longer a selfregulating profession? The role of scandals involving "bad apple" doctors', Social Science and Medicine, 73, 10, 1452-1459.

Elias, N. (2000), The Civilising Process, Oxford: Blackwell.

Ferguson, H. (2007), 'Abused and looked after children as "Moral Dirt": child abuse and institutional care in historical perspective', Journal of Social Policy, 36, 1, 123-139.

Flores, R. and Brown, P. (2018), 'The changing place of care and compassion within the English NHS: an Eliasean perspective', Social Theory \& Health, 16, 2, 156-171.

Flynn, R. (2002), 'Clinical governance and governmentality', Health, Risk \& Society, 4, 2, $155-173$.

Francis, R. (2013a), Report of the Mid Staffordshire NHS Foundation Trust Public Inquiry, London: The Stationary Office.

Francis, R. (2013b), 'Culture, compassion and clinical neglect-probity in the NHS after Mid Staffordshire', Journal of Medical Ethics, 41, 946-947. 
Galtung, J. and Ruge, M. (1965), 'The structure of foreign news: the presentation of the Congo, Cuba and Cyprus Crises in Four Norwegian Newspapers', Journal of Peace Research, 2, 1, 64-90.

Giddens, A. (1990), The consequences of modernity. Cambridge: Polity.

Giddens, A. (1991), Modernity and Self-Identity: self and society in the late-modern age, Stanford: Stanford University Press.

Greenhalgh, T. (2013), 'The compassionate organisation', British Journal of General Practice, $63,614,481$.

Habermas, J. (1976), Legitimation Crisis, Cambridge: Polity.

Habermas, J. (1987), Theory of Communicative Action: vol. 2, lifeworld and system, a critique of functionalist reason, Cambridge: Polity.

Habermas, J. (1989), The structural transformation of the public sphere: an inquiry into the category of bourgeois society, Cambridge: MIT Press.

Howe, G. (1969), Report of the committee of enquiry into the allegations of ill treatment of patients and other irregularities at Ely hospital, Cardiff, Cmnd3975, London: HMSO.

Hutchison, J. (2016), 'Scandals in health-care: their impact on health policy and nursing', Nursing Inquiry, 23, 1, 32-41.

Hughes, E., Kitzinger, J. and Murdock, G. (2006), The media and risk. In: P. Taylor-Gooby and J. Zinn (Eds.,) Risk in Social Science (pp. 250-270), Oxford University Press, Oxford.

Hunt, J. (2014), "Francis effect' on NHS care one year on from Mid Staffs Inquiry': press release via the Department of Health, https://www.gov.uk/government/news/francis-effect-onnhs-care-one-year-on-from-mid-staffs-inquiry [accessed 18 April 2016].

Jefferys, M. (2000), Recollections of the pioneers of the geriatric medicine specialty. In: J. Bornat, R. Perks, P. Thompson and J. Walmsley (Eds.), Oral History, Health and Welfare (pp. 75-97), Routledge, London.

Jolley, J. (2004), A social history of pediatric nursing: 1920-1970. Unpublished $\mathrm{PhD}$, thesis: University of Hull.

Jolley, J. and Shields, L. (2009), 'The evolution of family-centered care', Journal of Pediatric Nursing, 24, 2, 164-170.

Jones, K. (1993), Asylums and after: a revised history of the mental health services: from the early 18th century to the 1990s, London: Athlone.

Kitzinger, J. (2000), 'Media templates: patterns of association and the (re)construction of meaning over time', Media, Culture \& Society, 22, 1, 61-84.

Lindblom, C. (1959), 'The science of 'muddling through', Public Administration Review, $19,2,79-88$.

Lodge, M. and Hood, C. (2002), 'Pavlovian policy responses to media feeding frenzies? Dangerous dogs regulation in comparative perspective', Journal of Contingencies and Crisis Management, 10, 1, 1-13.

Luhmann, N. (1993), Risk: a sociological theory, New York: Aldine de Gruyter.

Lull, J. and Hinerman, S. (1997), Media Scandals: Morality and Desire in the Popular Culture Marketplace, New York: Columbia University Press.

Martin, J. and Evans, D. (1984), Hospitals in Trouble, Oxford: Blackwell.

Menzies Lyth, I. (1960), 'Social systems as a defense against anxiety: an empirical study of a nursing service in a general hospital', Human Relations, 13, 95-121.

Mol, A. (2008), The Logic of Care: Health and the problem of patient choice. London: Routledge.

Mold, A. (2010), 'Patient groups and the construction of the patient-consumer in Britain: an historical overview', Journal of Social Policy, 39, 4, 505-521.

Mold, A. (2015), Making the Patient Consumer: patient organisations and health consumerism in Britain, Manchester: Manchester University Press.

Moran, M. (2001), 'The rise of the regulatory state in Britain', Parlimentary Affairs, 54, 1, 19-34. Negrine, R. (1994), Politics and the Mass Media in Britain, 2nd edn, London: Routledge.

Newdick, C. and Danbury, C. (2013), 'Culture, compassion and clinical neglect: probity in the NHS after Mid-Staffordshire', Journal of Medical Ethics, 41, 956-962. 
Pollock, A. and Price, D. (2013), 'Mid-Staffordshire should lead to a fundamental rethink of government policy', British Medical Journal, 346, f2190.

Porter, R. (2005), A touch of danger: the bedside manners of the eighteenth century physician. In: C. Classen (Ed.) The Book Of Touch (pp. 377-383), Berg, New York.

Power, M. (2004), The risk management of everything: rethinking the politics of uncertainty, London: Demos.

Rader, J., Barrick, A., Hoeffer, B., et al. (2006), 'The bathing of older adults with dementia: easing the unnecessarily unpleasant aspects of assisted bathing', American Journal of Nursing, 106, 40-48.

Raghuram, P., Bornat, J. and Henry, L. (2011), 'The co-marking of aged bodies and migrant bodies: migrant workers' contribution to geriatric medicine in the UK', Sociology of Health and Illness, 33, 2, 321-335.

Robb, B. (1967), Sans everything: a case to answer, Edinburgh: Nelson.

Rodger, J. (2003), 'Social solidarity, welfare and post-emotionalism', Journal of Social Policy, $32,3,403-421$.

Rothstein, H. (2006), 'The institutional origins of risk: a new agenda for risk research', Health, Risk \& Society, 8, 3, 215-221.

Schei, E. (2006), 'Doctoring as leadership: the power to heal', Perspectives in Biology and Medicine, 49, 3, 393-406.

Smajdor, A. (2013), 'Reification and compassion in medicine: a tale of two systems', Clinical Ethics, 4, 111-118.

Smith, R. (1998), 'All changed, all changed utterly: British medicine will be transformed by the Bristol case', British Medical Journal, 316, 1917-1918.

Spector, M. and Kitsuse, J. (1977), Constructing Social Problems, 4th edn, New Brunswick: Transaction.

Stimson, G. and Webb, B. (1975), Going to see the doctor, London: Routledge \& Keegan Paul.

Taylor-Gooby, P. (2012), 'Why do people stigmatise the poor at a time of rapidly increasing inequality, and what can be done about it?', The Political Quarterly, 84, 1, 31-42.

Thelen, T. (2014), Care/Sorge: Konstruktion, Reproduktion und Auflösung bedeutsamer Bindungen, Bielefeld: transcript Verlag.

Tonkens, E. (2012), 'Working with Arlie Hochschild: connecting feelings to social change', Social Politics, 19, 2, 194-218.

Tronto, J. (2010), 'Creating caring institutions: politics, plurality, and purpose', Ethics and Social Welfare, 4, 2, 158-171.

Turner, B.A. and Pidgeon, N.F. (1997), Man-made disasters, 2nd edn, Oxford: ButterworthHeinemann.

Warner, J. (2006), 'Inquiry reports as active texts and their function in relation to professional practice in mental health', Health, Risk and Society, 8, 3, 223-237.

Warner, J. (2015), The emotional politics of social work and child protection, Bristol: Policy Press.

Wilkinson, I. (2010), Risk and vulnerability in everyday life, London: Routledge.

Winnett, R. and Brogan, B. (2013) Stafford scandal: Jeremy Hunt calls for police inquiry into NHS. The Telegraph, 8 February.

Wouters, C. (2007), Informalization: Manners and emotions since 1980, London: Sage. 